\title{
A abordagem proibicionista em desconstrução: compreensão fenomenológica existencial do uso de drogas
}

\author{
Deconstructing the prohibitionist approach: \\ a phenomenological existential understanding of drug abuse
}

M arcelo Sodelli ${ }^{1}$

\footnotetext{
${ }^{1}$ FaculdadedeCiências HumanasedaSaúde, Departamento dePsicologia,

Pontifícia U niversidade Católica de São Paulo. Rua Veríssimo Glória 165, Sumaré. 01251-140 São Paulo SP.

msodelli@pucsp.br
}

Abstract The present article aims to deconstruct the Prohibitionist Model against drug abuse. Understanding $M$ an as an unfinished being, always left to his own care, the study demonstrates the incompatibility of the Prohibitionist objectives with M an's unique way of being. We show that it is the very existential condition of $M$ an that generates what we call "existential vulnerability", a condition that is impossible to be modified. In fact, we argue that any preventive approach whose fundamental principle is the eradication of drug abuse would be prone to failure. Based on this positioning, we reject the Prohibitionist view according to which "drug abuse" is always and invariably a deviant behavior (pathology). Finally, the study points to the importance of the development of a new preventive approach that fully absorbs the uniqueness of the human condition (existential vulnerability), definitely breaking with the prohibitionist precepts, in fact, the $\mathrm{H}$ arm Reduction Approach.

Key words Drugs, Prevention, Phenomenology, Prohibitionism
Resumo 0 presente artigo pretende, por meio do pensamento da fenomenologia existencial, desconstruir o modelo proibicionista ao uso de drogas. Ao compreender o homem como um ser inacabado, sempre entregue ao seu próprio cuidado, o estudo caminhará na direção de demonstrar a incompatibilidadedos objetivos proibicionistas com o modo singular de ser do homem. Demonstraremos que é a própria condição existencial do homem que gera o que nomearemos como "vulnerabilidade existencial", condição esta impossível de ser modificada. Com efeito, argumentaremos que qualquer abordagem preventiva que tenha como princípio fundamental erradicar o uso de drogas já estaria fadada ao fracasso. Fundamentando-nos ainda neste posicionamento, rejeitaremos a compreensão proibicionista que o "uso de drogas" é sempre e invariavelmente um comportamento desviante (patologia). Por fim, o estudo aponta para a importância do desenvolvimento de uma nova abordagem preventiva que absorva de modo integral a singularidade da condição humana (vulnerabilidade existencial), rompendo definitivamente com os preceitos proibicionistas, a saber, a abordagem de redução de danos.

Palavras-chave Drogas, Prevenção, Fenomenologia, Proibicionismo 
Introdução

Podemos perceber, nos últimos anos, intensa produção de pesquisas que se dedicaram a estudar um dos mais utilizados modelos de prevenção ao uso nocivo de drogas, a saber, intolerância e guerra contra as drogas (proibicionismo). Observamos, também, quea mai oria destas pesquisas se posicionou criticamente a esta abordagem, avaliando-a como ineficaz eirrealista ${ }^{1,2}$. Esta discussão ganhou dimensão ainda maior com o surgimento no Brasil, no fim da década de oitenta, da abordagem de redução de danos e, posteriormente, da sua aplicação na área preventiva ao uso de drogas.

Pesquisas recentes ${ }^{3,4}$ apontam que um dos elementos principais que explica o fracasso da abordagem proibicionistaéjustamenteo queestá na base de seus pressupostos preventivos: a pre conização da abstinência.

Embora vasta a literatura sobre este tema, poucos são os estudos que discutem, com base numa fundamentação teórica, as limitações e consequências da abordagem proibicionista na área preventiva.

Partindo desta compreensão, o presente artigo pretende, por meio do pensamento dafenomenologia existencial, realizar um estudo reflexivo sobre a condição humana e o uso de drogas. Ao compreender o homem como um ser inacabado, sempre entregue ao seu próprio cuidado, o estudo caminhará na direção de demonstrar a incompatibilidade dos objetivos proibicionistas com o modo singular de ser do homem. Demonstrare mos que é a própria condição existencial do homem que gera o que nomearemos como "vulne rabilidade existencial", condição esta impossível de ser modificada. Com efeito, argumentaremos que qualquer abordagem preventiva que tenha como princípio fundamental erradicar o uso de drogas já estaria fadada ao fracasso. Fundamentando-nos ainda neste posicionamento, rejeitaremos a compreensão proibicionista que o "uso de drogas" ésempre einvariavelmente um comportamento desviante (patologia). Por fim, apresentaremos a abordagem de redução de danos como uma nova alternativa na prevenção primária.

Ressalvamos que a compreensão fenomenológica existencial apresentada nesteartigo se sustenta, exclusivamente, na discussão feita por $\mathrm{H}$ eidegger, em sua obra "Ser eTempo" ${ }^{5}$.U tilizaremos, também, outros autores que compartilham deste modo de compreender o existir humano, entre outros: M edard Boss, Benedito Nunes e Zeljko Loparic.
O homem

na perspectiva fenomenológica existencial

Uma das maiores contribuições do pensamento fenomenológico existencial éa simples, mas importante constatação de que não podemos estudar e compreender o homem da mesma forma como o fazemos com outros seres e objetos. Podemos distinguir duas condições fundamentais entre esses entes (tudo que existe, todos os seres vivos e objetos) eo Dasein, termo proposto pelo próprio $\mathrm{H}$ eidegger ${ }^{5}$ para indicar o caráter peculiar e distinto da existência humana. Dasein é 0 homem compreendido como o ser-existindo-aí. Dasein é sempre uma possibilidade na qual se encontra como uma abertura para a experiência.

A primeira condição fundamental é que 0 Dasein é o único ser que sabe da sua finitude, de queum dia sua vida vai terminar, dequeeleéum ser mortal. Desde o princípio, o Dasein está predeterminado pelo seu fim ${ }^{6}$. 0 homem sabe que um dia virá em que ele não mais "será" ou "existirá". Para a fenomenologia existencial, esta diferença marca um modo distinto do homem estar no mundo, muito diferente dos outros entes, uma vez que é o único ser que tem de conviver com o seu-ser-para-a-morte e é livre para realizar uma opção entre viver ou morrer. Desta condição ontológica, nascem dois sentimentos inerentes ao Dasein: a angústia e a culpa.

A ameaça do não-ser (a morte) é a fonte da angústia primordial do Dasein, a qual vivenciamos por meio do confronto entre a necessidade de realização das nossas potencialidades eo perigo de não ser capaz de realizá-las. Cada angústia humana tem um de que, do qual ela tem medo, e um pelo que, pelo qual ela teme. 0 deque de cada angústia compreende a possibilidade real do Dasein de um dia não estar mais aqui. 0 pelo que da angústia nos remete à própria condição existencial do Dasein, ou seja, a responsabilidade de zelar e cuidar de sua continuidade no mundo?.

A culpa é outra importante singularidade do modo de ser do Dasein, a qual não está relacionada às proibições ou tabus culturais, mas, fundamentalmente, à consciência de que o ser do Dasein está sempre em jogo. Consciência deve ser entendida aqui como o "saber junto - com", quer dizer, o Dasein é convocado por ele mesmo a dar conta do seu ser (existir) ${ }^{8}$. Conhecer esta tarefa é ter consciência do apelo do ser, do estaraí-no-mundo.

Deste modo, temos sempre que escolher um modo de ser e, como tal, podemos falhar nesta escolha. A culpa então sevincula à consciência da 
não-realização integral das potencialidades, da necessidade imperativa de efetuar certas escolhas, em detrimento de outras. Para melhor entendermos o sentimento de culpa, vejamos a segunda diferença fundamental entre o Dasein e os outros entes.

A segunda condição fundamental é que 0 homem nasce com o seu ser livre. 0 Dasein é essencialmente livre, no sentido de ser capaz de realizar opções e de tomar decisões das quais re sultam os significados de sua existência. Os outros animais já nascem destinados a serem eles mesmos, pois não têm a possibilidade de ser outra coisa. Por exemplo, uma abelha já nasce abelha, não há outra possibilidade, a não ser, existir como abelha. Por outro lado, o homem nasce possibilidade e não determinação.

Na compreensão fenomenológica existencial, o homem se torna Dasein unicamentena sua re lação de ser-com-os-outros (humanos). Dasein é sempre uma possibilidade, na qual se encontra uma abertura para a experiência. 0 homem é 0 ser-existindo-aí.

Entretanto, o Dasein não existeisoladamente sem o mundo que habita que, por sua vez, também não existe separado do Dasein. Quer dizer, o homem não é uma simples "coisa" no meio de outras coisas, nem uma interioridade fechada dentro de si mesmo. Daí a importância de compreender a expressão fenomenológica "ser-nomundo", que aponta primeiramente para um fenômeno de unidade eédeste modo que devemos compreendê-la. Esta expressão deve ser entendida como uma estrutura de realização, visto quea existência do homem como "ser-no-mundo" se desenvolve num mundo de realizações, interesses e explorações, de lutas e fracassos 5 .

Porém, mesmo sendo possibilidade, o homem não vive solto no mundo, sem rumo. Ao contrário, por sua condição ontológica de abertura, de ter-que-ser alguma coisa, todo o tempo, o homem se entrelaça no mundo, por meio da busca incessante pelo sentido. 0 sentido da existência consiste no estar-lançado-no-mundo, como seu destinar-se, seu rumo. E é esse sentido da existência que vai impulsionando e pressionando a mundanização de nosso mundo, toda a ambientação de nosso lugar de vida, nosso trabalho, nosso fazer. Assim, a força motivadora da vida humana é a busca que o homem empre ende para dar um sentido à sua existência9.

Como já discutimos, ao dar-se conta de ser, de poder-ser, o homem percebe que tem que dar conta de seu ser, ou seja, tem que dar conta de sua existência e, sobretudo, isto está sob sua res- ponsabilidade. Assim, o homem tem que "cuidar deser". Os homens tomam para seu cuidado tudo o que pertence à existência: o mundo, as coisas do mundo, os outros homens, si mesmos. Heidegger ${ }^{5}$ define como "cuidado" o habitar o mundo econstruí-lo, preservar a vida biológica eatender suas necessidades, tratar de si mesmo e dos outros. É o "cuidado" que torna significativas a vida ea existência humana. Ser-no-mundo, portanto, é cuidar ${ }^{10-12}$.

Após essa breve apresentação, podemos iniciar uma compreensão sobre as relações entre o homem e o uso de drogas, com base na perspectiva fenomenológica existencial.

Um olhar fenomenológico existencial: aproximações ao fenômeno do uso de drogas

Ao examinarmos a condição humana, na perspectiva fenomenológica existencial, é possível rapidamente entender por que o uso de drogas se fez presente, pelo menos até onde sabemos, desde as civilizações mais antigas, como os fenícios (4.000 a.C.), por exemplo13. Documentos antigos descrevem a produção de cerveja por meio da fermentação do pão, que continua até os dias dehoje.

A presentamos anteriormente que, para a fenomenologia existencial, o homem possui duas condições ontológicas fundamentais: ser mortal e ser livre. $\mathrm{Na}$ vida cotidiana, essas duas condições existenciaissão vivenciadas onticamentepor meio dos sentimentos da angústia e da culpa. Por ser uma condição existencial do Dasein ter quecuidar do próprio existir, dando sentido para as coisas do mundo, e mais, sabendo que é impossível transferir esta tarefa para outro, por estas razões, o mundo pode se tornar um lugar inóspito, a vida pode ser sentida como um ônus, como um fardo que se tem de carregar.

Nesta mesma direção, Loparic ${ }^{9}$ alerta que 0 perigo que nos espreita e em toda parte nos acua é o mundo como mundo, originário e diretamente, que se abre para o D asein desabrigado. 0 mundo inteiro não o pode completar. Conscientedisto, o Dasein experimenta a angústia edesespero, dor etédio. Essa consciência revela a essencial vulnerabilidadeexistencial do ser humano. É desta vulnerabilidade existencial que se origina a abertura para o possível uso de drogas. É frente à angústia do futuro estrangeiro que se abre a possibilidade do uso de drogas como promessa de um viver maistranquilo. Assim, o uso dedro- 
gas vai revelar-se como uma das possibilidades de alívio do cuidar, na precariedade do viver ${ }^{14}$. É claro que não é só por meio do uso de drogas que o homem busca o alívio do ter quecuidar do seu próprio ser. Outras atividades também podem proporcionar esta sensação, por exemplo, assistir a um bom filme, praticar esportes, participar de um culto religioso, ter um relacionamento sexual. Todas essas atividades podem nos possibilitar momentos prazerosos, nos quais experimentamos um desligar automático danossa árdua tarefa do cuidar do nosso próprio ser, ou seja, podem provocar uma alteração do estado da consciência.

H istoricamente, éinegável queo ser humano vem se dedicando a criar vários métodos para alterar a consciência, como dançar, jejuar, meditar eaté mesmo criar atividades que colocam em risco sua própria vida, como o automobilismo, a escalada e tantas outras experiências ${ }^{15}$. Esta particularidade da condição existencial do homem não deve ser compreendida como uma faIha do ser humano, mas sim como al go que possibilita a ampliação da criatividade. Esta condição humana é que nos possibilita ultrapassar nossos próprios limites e na qual reside toda a nossa contradição de ser humano, pois que, ao mesmo tempo em quetemos o potencial decriar a poesia mais bonita, somos capazes de pensamentos e de atos de extrema barbaridade.

A incessante busca do ser humano em alterar o estado da consciência também é reconhecida pela antropologia. Por exemplo, nas mais diversas sociedades e culturas estudadas por antropólogos e por outros cientistas sociais, encontramos algum tipo de situação, algum momento em que não só é permitido, como pode ser inclusive valorizado, um tipo de alteração de comportamento, alteração deatitudeem relação a uma roti$n a^{16}$. Essa alteração pode ou não estar associada ao uso de substâncias que chamamos de drogas.

Na compreensão fenomenológica existencial, o ser humano, por sua própria constituição ontológica, se apresenta vulnerável em relação ao cuidar do seu existir. Esta vulnerabilidade, por sua vez, possibilita uma procura interminável em minimizar os sentimentos deangústia e de culpa.

Compreendemos, assim, por meio do pensamento fenomenológico existencial, que é impossível acabar com a possibilidade do uso de drogas entre os seres humanos, pois, para isto acontecer, seria necessário modificar a própria condição ontológica do Dasein. Destemodo, todo e qual quer esforço, seja de caráter preventivo ou de tratamento ao uso nocivo de drogas, quepre- tenda universalmente negar esta possibilidade humana, estará fadado ao fracasso.

Torna-se possível, então, considerar a questão do uso de drogas como uma entre tantas outras possibilidades de alterar nossa consciência, de diminuir o sofrimento ea angústia existencial. A história da humanidade nos ensina que o uso de drogas é apenas um modo de vida. As pessoas sempre as utilizaram, por motivos os mais diversos, e sem dúvida, seguirão utilizando-as ${ }^{17}$.

Mas, por que é tão perturbador pensar desta maneira? Por que é tão difícil aceitarmos a idéia de que o fenômeno do uso de drogas seja avaliado da mesma maneira como qualquer outro fenômeno que busca a alteração da consciência?

Dependência e danos à saúde: inevitabilidade do uso de drogas?

A resposta mais imediata é que o uso de drogas pode causar algum dano à saúde e pior, pode causar também uma grave patologia, o fenômeno da dependência. Vale lembrar que esses estão entre os principais argumentos que justificam a atual política mundial da intolerância e de repressão ao uso de drogas, o modelo preventivo da intolerância e da guerra contra as drogas.

0 primeiro argumento, a nosso ver, é indiscutível: realmente, o uso de drogas pode causar danos à saúde. Entretanto, existem diversas outras coisas que também podem causar danos à saúde, eque, mesmo assim, continuamos a fazer todos os dias. Tomemos como exemplo a questão da poluição: em última instância, nós a produzimos, já cientes de que ela vai prejudicar não só a nós, mas também as gerações futuras. Sabemos também que ocorrem, por ano, muito mais acidentes fatais no trânsito do que em decorrência do uso nocivo de drogas ou de overdose, e, mesmo assim, milhões de pessoas continuam utilizando diariamente seus automóveis.

0 que estamos tentando demonstrar não é, de forma alguma, o argumento de que, já que está tudo errado no mundo, não existe sentido em nos preocuparmos com os possíveis danos do uso de drogas. Pelo contrário, estamos tentando mostrar outro aspecto: assim como tentamos minimizar os danos causados pela poluição e pelo trânsito, através de regulamentos, informações, infraestrutura e, principalmente, da educação, deveríamos, também, assumir definitivamente esta postura perante a questão das drogas.

Sabemosquenão é possível pensar uma grande cidade sem os riscos de acidentes de trânsito, 
mas também estamos cientes de que há uma grande diferença entre aquelas cidades, cujas estradas são cuidadas, em que há o planejamento do trânsito urbano, que oferecem transporte seguro para a população, daquelas que não tomam essas providências. Em vez de proclamar uma tola proibição, devemos reconhecer que 0 desejo de drogas recreativas é tão legítimo quanto inextinguível eque é preferível reduzir os danos associados a elas a fingir que está tudo bom apenas com a manutenção da ideologia da proibição - mas na realidade promovendo um consumo extremamente inconsciente, desfavorável, desimpedido, descontrolado e desenfreado ${ }^{15}$.

N ovamente, voltamos à nossa posição inicial. Afirma o autor citado acima que é impossível acabar com o desejo humano em usar as drogas, ou seja, fenomenologicamentefalando, éimpossível modificar a condição ontológica do ser humano. Assim, o argumento de que o uso de drogas causa danos à saúde, a nosso ver, não é suficientenem satisfatório para sustentar um modelo da intolerância e da guerra contra as drogas.

0 segundo argumento éque o uso de drogas pode causar uma grave patologia: a dependência. Vejamos como o olhar fenomenológico existencial pode contribuir para ampliarmosnossa compreensão sobre este fenômeno. Afirmamos anteriormente que uma das principais características do homem é a sua condição existencial de ser livre. Ao mesmo tempo em que este modo de estar no mundo é sentido como algo prazeroso, que abre infinitas possibilidades, também é sentido como um problema que tem que ser resolvido a todo tempo: sempre sou chamado a decidir sobre o modo como vou cuidar do meu ser-livre.

Dessemodo, o sentido da minha vida, o modo como eu a vivo, aquilo que está sob minhas mãos, é de minha inteira responsabilidade. 0 sentido que ser faz para cada um denós, individualmente ou coletivamente, revela-sena nossa relação com o mundo, no qual vamos tecendo e estruturando nossa vida cotidiana ${ }^{18}$. É o cuidado que torna significativas a vida e a existência humana. E é justamente por esta abertura existencial (ser-livre) que o uso de drogas pode causar um estreitamento do modo de cuidar de ser, ou seja, na liberdade de ser.

Podemos observar que é muito comum, no início do uso de drogas, o usuário experimentar um modo de estar no mundo completamente diferente daquele modo cotidiano de $\operatorname{ser}^{14}$. Ou seja, na compreensão fenomenológica, o uso de drogas pode proporcionar, mesmo de maneira fugaz, um modo mais agradável de estar no mundo, como se a própria condição existencial tivesse sido mudada. Os desdobramentos desta experiência vão depender do modo como cada um cuida do seu ser, do modo como compreende o sentido de seu ser-no-mundo. Como, na compreensão fenomenológica, o sentido de serno-mundo não é al go passível de ser determinado, qualquer tentativa de prever os desdobramentos do modo de ser do Dasein estará destinada ao equívoco. Especificamente em relação ao uso de drogas, isto será revelado vivencialmente (onticamente) pelos variados padrões de uso (experimentador, ocasional, habitual e dependente) e modos de uso (controlado, de risco enocivo). Assim, podemoscompreender por que o fenômeno da dependêncianão éuma condição imutável ou, dito em outros termos, um dependente não está de forma alguma determinado a ser dependente para sempre.

Outros autores ${ }^{19-21}$, ao discutirem os fatores que determinam o padrão de uso do usuário de drogas, acabam revelando uma compreensão que pode ser aproximada à postura fenomenológica. Ressaltam eles que não se pode referir ao padrão do uso de drogas apenas pelas propriedades farmacológicas das substâncias, mas por um conjunto de fatores intrínsecos: a droga, o indivíduo e o meio social. Ou seja, na relação do homem com o mundo (droga e meio social); a partir do modo de cuidar de ser; da trama do sentido de ser-no-mundo.

Consideramos que, neste momento, após a desconstrução da abordagem proibicionista, estamos aptos a apresentar uma nova possibilidade de trabalho preventivo. Assim, apresentaremos a seguir, a abordagem de redução de danos como uma nova possibilidade preventiva.

\section{A redução de danos na prevenção primária}

A redução de danos teve origem na Inglaterra, em 1926, com as recomendações de um relatório queficou conhecido como "Relatório Rolleston", que estabelecia o direito de os médicos ingleses prescreverem suprimentos regulares de opiáceos a dependentes dessas drogas.

Porém, só no início da década de oitenta, na H olanda, é que os princípios da proposta de redução de danos (RD) começaram a ser sistematizados em formas de programas. Por iniciativa de uma associação de usuários de drogas, foi realizada uma ousada proposta para combater uma epidemia de hepatite $B$ entre usuários de drogas intravenosas (UDI). Logo em seguida, o sistema 
de saúde holandês adotou esse programa e começou a distribuir seringas, para evitar que elas fossem compartilhadase, assim, diminuir a transmissão da doença entre os UDI.

0 programa de RD tem um princípio simples: éuma política social cujo objetivo prioritário é minorar os efeitos negativos decorrentes do uso de drogas. Por exemplo, em relação ao uso de droga injetável, constatada a dificuldade ou a falta de vontade dos usuários em abandonar a utilização da substância, a idéia é criar alternativas para diminuir o dano causado.

0 primeiro ponto a esclarecer é referente ao entendimento da abordagem de redução de danos como prevenção primária. Sabe-se quea pre venção podeser dividida em três modos de intervenção:

- A prevenção primária refere-se ao trabal ho que é feito com pessoas (alunos) que ainda não experimentaram, ou que estão na idade em que possivel mente pode se iniciar o uso de uma droga lícita ou ilícita;

- A prevenção secundária tem como objetivo atingir as pessoas quejá experimentaram ou que fazem um uso ocasional de drogas, com intuito de evitar que este padrão de uso se torne problemático ou abusivo (uso habitual);

- A prevenção terciária corresponde aos usuários que já apresentam problemas (uso problemático, uso habitual) e a intervenção preventiva éfeita para que eles não cheguem à dependência.

Ao descrever estes três modos de prevenção, poderíamos refletir que os pressupostos da abordagem de redução de danos não teriam sentido na prevenção primária, já que esta intervenção é indicada para os indivíduos que ainda não tiveram nenhuma experiência com o uso de drogas. Poderíamos perguntar como seria possível reduzir danos em pessoas que ainda nem fizeram uso de drogas. Ou ainda, procurar saber como seria o trabalho preventivo na escola, considerando um projeto preventivo desenvolvido na educação infantil ou no ensino fundamental. E mais: quetipo de formação estaríamos propondo às crianças?

Considerando que o conceito proibicionista está arraigado em nossa cultura educativa, uma ferramenta utilizada largamente, no âmbito escolar, resumida no conceito "não pode porque não pode", uma das principais dificuldades seria não saber qual pressuposto colocar no lugar da mera proibição. Possivelmente, muitos argumentariam que, se não trabal harmos os conceitos de proibição e abstinência, na prevenção primária, entre e com aqueles que ainda não experimentaram alguma droga, o consumo de drogas iria aumentar consideravelmente na adolescência, correndo-se o risco de perder o pouco controle sobre os jovens que ainda se tem.

A idéia de relacionar a redução de danos como prevenção primária é para reafirmar a posição de que o objetivo da prevenção não deveria ser o de acabar com o uso de drogas, pois, como já demonstramos, esta é uma tarefa impossível. Logo, trabalhos preventivos que preconizam somente a proibição do tipo "não pode porque não pode" vêm se mostrando ineficazes no lidar com a problemática do uso de drogas. Assim, a prevenção deveria, fundamentalmente, assumir a tarefa de intervir na redução dos níveis de vulnerabilidade ao uso nocivo das substâncias psicoativas.

Trabalhar a prevenção às drogas na perspectiva da abordagem de redução de danos, na prevenção primária, é compreender que o melhor caminho para lidar com o fenômeno do uso de drogas não é o de decidir e definir pelos outros quais os comportamentos mais adequados e corretos. M uito diferentedisso, éconstruir, junto com o outro, possibilidades de escol has mais autênticas, mais livres, diminuindo vulnerabilidades.

A partir desta abordagem, o comportamento de "experimentar uma droga" não deveria ser compreendido como uma fal ha no trabal ho preventivo primário, mas sim, uma possibilidade, entre outras, do existir humano. Desta maneira, só poderíamos dizer que houve fal ha na intervenção preventiva primária se este experimentar evoluir para o uso nocivo de drogas.

Todas as objeções colocadas a esse modo de trabal har a prevenção estão sustentadas pela idéia equivocada de que trabal har a proibição e a abstinência, na prevenção primária, contribui para o desenvolvimento de comportamentos mais seguros em relação ao uso de drogas. Podemos facilmente perceber aí uma contradição: como podemos esperar comportamentos mais seguros no uso de drogas, se nem ao menos discutimos esta possibilidade na prevenção primária?

Seguindo nossa linha deargumentação, o sentido da prevenção seria diminuir os riscos associados ao uso de drogas, entre os quais destacamos o padrão de uso habitual ou de dependência, dirigir sob o efeito de al guma substância psicoativa, overdose, o compartilhamento de seringas ou de cachimbos, o uso de drogas associado a comportamentos de risco (sexo sem proteção, esportes radicais.), violência, etc.

Considerando esta perspectiva, a questão do uso de drogas passa a ser compreendida de outra maneira: as drogas não devem ser classificadas a priori como substâncias maléficas, mas sim, 
como substâncias neutras. Só poderíamos valorizar as drogas, na relação com o homem, nesse contexto em que se estabelece o sentido do uso, seja um uso recreacional, medicinal, nocivo, compulsivo, entre outros.

Ao relacionar o modelo de redução de danos à prevenção primária, estamos propondo muito mais que um novo modelo preventivo: estamos oferecendo um modelo de educação preventiva. Em outras palavras, que homem desejamos formar e que sociedade pretendemos construir.

\section{Consideraçõesfinais}

Não desconsiderando a força do modelo proibicionista, fomos buscar, na compreensão fenomenológica existencial, argumentos para desconstruir essa visão determinista e fatalista sobre a relação do homem com as drogas.

Embora nosso estudo fenomenológico existencial não possa ser entendido como uma profunda investigação da condição humana, foi suficiente para nos revelar outras possi bilidades da relação do homem com as drogas e abrir novas alternativas para 0 desenvolvimento de projetos preventivos ao uso nocivo de drogas.

Sem dúvida, uma das maiores contribuições deste estudo foi a compreensão de que a idéia de acabar com o uso de drogas entre os seres humanos é irreal, pois, para isto acontecer, seria necessário modificar a própria condição ontológica do homem (a tarefa intransferível de cuidar do seu próprio existir). Destemodo, todo equalquer esforço, seja de caráter preventivo ou de tratamento ao uso de drogas, que pretender universalmente negar esta possibilidade humana, estará fadado ao fracasso.

A compreensão fenomenológica existencial nos mostrou também que o sentido de ser-nomundo não é algo passível de ser determinado; qual quer tentativa de prever os desdobramentos do modo de ser do Dasein estará destinada ao equívoco. Especificamente em relação ao uso de drogas, isto é revelado vivencialmente, pelos variados padrões de uso (experimentador, ocasional, habitual edependente), como também pelos modos de se relacionar com as drogas (uso controlado, derisco enocivo). Assim, podemos compreender, primeiro, que o uso de drogas não leva necessariamente a uma patologia e segundo, que o fenômeno da dependência não éuma condição imutável ou, dito de outra forma, um dependente não está de forma alguma determinado a ser dependente para sempre.

Ao chegarmos por meio da fenomenologia existencial à compreensão sobre a impossibilidade demudar a condição existencial do homem e, consequentemente, a sua disposição em relação ao uso de drogas, identificamos, na abordagem de redução de danos, um terreno fértil para firmarmos um novo objetivo preventivo: reduzir vulnerabilidades ao uso nocivo de drogas. Estabelecemos, assim, um contraponto à abordagem proibicionista, ou seja, em vez de trabaIhar somente a abstinência e a repressão, o sentido da preven ção deveria ser o de promover ações redutoras de vulnerabilidades ao uso nocivo de drogas. É nesse sentido que entendemos o entrelaçamento da prevenção primária ao uso dedrogas com a abordagem de redução de danos e, mais especificamente, no âmbito escolar, a possibilidade da construção permanente de uma rede cuidadora entre o professor e 0 aluno.

Ao dial ogar com outros interesses, sem ser 0 do controle, o da proibição, o sentido da prática preventiva se modifica, assim como o seu modo de dialogar. Portanto, não éo técnico (professor, psicólogo, médico, etc.) que determinará como o sujeito-alvo (aluno, professor) deveria se prevenir, mas éo próprio sujeito, após intensa reflexão, que se colocará em questão, buscando formas e apoio para reduzir suas vulnerabilidades.

Considerando a abordagem de redução de danos na prevenção primária, podemos indagar se não seria um dos sentidos da prevenção a tentativa concreta de contribuir para o cuidar de si mesmo etambém do outro. Ora, considerar esta abordagem éreconhecer a importância de possibilitar para o aluno a construção de seu projeto de vida ou, em outras palavras, encorajar no aluno o poder de transformação, que estamos nomeando hoje como a possibilidade de construir sua plena cidadania.

A insistência em preconizar o modelo proibicionista, a pedagogia do controle, o distanciamento do sentido de educar do sentido de prevenir, poderá custar a todos nós a perpetuação da inexistência deum autêntico trabal ho de prevenção ao uso nocivo de drogas no âmbito escolar. Ou seja, o esquecimento deum dos sentidosmais próprios da educação: reduzir vulnerabilidades. 


\section{Referências}

1. Canoletti B, Soares CB. Drug consumption prevention programs in Brazil: analysis of the scientific production from 1991 to 2001. Interface (Botucatu) 2005; 9(16):115-129.

2. Moura RAC. 0 diálogo entre as políticas, as pesquisas acadêmicas e a práxis de prevenção ao indevido de drogas nas escolas [dissertação]. São Paulo (SP): Faculdade de Psicologia, Pontifícia Universidade Católica; 2004.

3. Sodelli M. Aproximando sentidos: formação de professores, educação, drogas e ações redutoras de vulnerabilidade [tese]. São Paulo (SP): Faculdade de Psicologia, Pontifícia Universidade Católica; 2006.

4. Tavares-De-Lima FF. Prevenção ao uso de drogas: modelos utilizados na educação, suas relações e possibilidade quanto a atitudes preventivas [dissertação]. São Paulo (SP): Faculdade de Psicologia, Pontifícia Universidade Católica; 2003.

5. Heidegger M. Ser e o Tempo. 4a ed. Petrópolis: Vozes; 1993.

6. Nunes B. Heidegger e ser e tempo. Rio de Janeiro: Jorge Zahar; 2002.

7. Boss M. Angústia, Culpa e Libertação. São Paulo: Livraria Duas Cidades; 1975.

8. Inwood MJ. Dicionário Heidegger. Rio de Janeiro: Jorge Zahar; 2002.

9. Loparic Z. Heidegger. Rio de Janeiro: Jorge Zahar; 2004.

10. Safranski R. H eidegger, um mestre na Alemanha entre o bem e o mal. São Paulo: Geração Editorial; 2000.

11. Critelli DM. Analítica do sentido: uma aproximação e interpretação do real de orientação fenomenológica. São Paulo: EDUC/Brasiliense; 1996.

12. Loparic Z. Além do inconsciente: sobre a desconstrução heideggeriana da psicanálise. $\mathrm{N}$ atureza $\mathrm{Hu}$ mana 2001; 3(1):91-140.

13. Seibel SD, Toscano Jr A. Conceitos básicos e classificação geral das substâncias psicoativas. In: Seibel SD, Toscano Jr A. Dependência de drogas. São Paulo: Atheneu; 2001.
14. Sipahi FM, Vianna FC. A dependência de drogas e a fenomenologia existencial. Revista da Associação Brasileira de Daseinsanalyse 2002; 11:85-92.

15. Scheerer S. Dominação ideológica versus lazer psicotrópico. In: Ribeiro M M, Seibel SD, organizadores. Drogas: hegemonia do cinismo. São Paulo: Memorial; 1997. p.287-300.

16. Velho G. Drogas, níveis de realidade e diversidade cultural. In: Ribeiro MM, Seibel SD, organizadores. Drogas: hegemonia do cinismo. São Paulo: Memorial; 1997. p.61-69.

17. Toscano Jr. A. Um breve histórico sobre o uso de drogas. In: Seibel SD, Toscano Jr. A. Dependência de drogas. São Paulo: Atheneu; 2001. p.7-24.

18. Heidegger M. Seminário de Zollikon. São Paulo: EDUC; Petrópolis: Vozes; 2001.

19. Macrae E. A excessiva simplificação da questão das drogas nas abordagens legislativas. In: Ribeiro M M, Seibel SD, organizadores. Drogas: hegemonia do cinismo. São Paulo: Memorial; 1997. p.327-334.

20. Baratta A. Introdução a uma sociologia da droga. In: M esquita F, Bastos FI, organizadores. Drogas e AIDS - estratégias de redução de danos. São Paulo: Hucitec; 1994. p.21-44.

21. Bucher R. Drogas o que é preciso saber. São Paulo: M elhoramentos; 1992.

Artigo apresentado em 24/04/2007

Aprovado em 14/08/2007

Versão final apresentada em 04/12/2007 